\title{
EL MORALISMO E ITALIA EN PELIGRO DE MUERTE
}

\section{Prefacio tranquilizante}

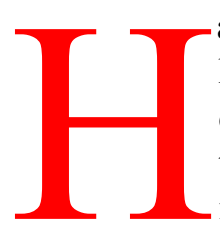

ay que comenzar diciendo que es la corrupción, antes que el moralismo, la que ha sumido a Italia en la crisis que parece ahogarla, sin duda la más grave desde el final de la II Guerra Mundial. Esto es una cuestión de verdad, pero también de prudencia, dado que la atmósfera del país es de denuncia inmediata de toda expresión que desentone. No hace falta decirlo. No habría una atmósfera como la actual, no se habría dado la explosión de moralismo si la corrupción a nivel del Gobierno -en el sentido amplio de la expresión- no hubiera alcanzado récords y desencadenado la rabia popular contra una élite que no sólo la practicaba como método común de administración, sino que la justificaba y trataba de legalizar. Se recuerdan las palabras de un ministro pidiendo que las tangenti fueran reconocidas por la ley. Nos dimos cuenta de que a la élite que detentaba el poder le hubiera gustado introducir un sistema de doble justicia, como durante la Edad Media: uno para ella y otro para los ciudadanos comunes. No es casual que el Ministerio de Justicia se convirtiera en la apuesta central de toda negociación para la formación de un Gobierno, aunque su presupuesto haya estado siempre entre los más pobres. Y todo el mundo sabía que existía más que una simple sospecha de que entre mafia y Gobierno, política y economía había siempre relaciones si no estructuradas, al menos constantes. Ninguna sorpresa: eso que acabamos de decir, incluso mucho más, ya había sido denunciado no sólo por los sectores no controlados de la prensa o por la oposición política a las coaliciones que se repetían desde hacía casi cuarenta y cinco años, sino también por el mismo presidente de la República, Francesco Cossiga, quien durante dos años lo había denunciado ante una audiencia sorprendida, tanto en el interior como en el extranjero. 
Pero ¿hace falta añadir que referirse a la corrupción no es suficiente para explicar lo que sucede en Italia?

Después de todo, la corrupción política se manifiesta en cualquier sistema político $\mathrm{y}$, fundamentalmente, en un país que, como Italia, no ha sufrido ningún cambio sustancial desde 1945 y en el que, por lo tanto, la élite tradicional ha cristalizado en el poder en mayor medida que en cualquier otra democracia occidental. Casi no pueden contarse los escándalos que han agitado los debates públicos en las décadas de postguerra y que han alcanzado a veces a las capas más altas del Estado. En 1978 un ministro fue condenado y encarcelado por el caso Lockheed. El presidente de la República, Giovanni Leone, fue obligado a dimitir en el mismo periodo. En 1981 el descubrimiento de la logia masónica P2 desencadenó una sucesión dramática de hechos, entre otros la crisis de Rizzoli -la gran editorial que controlaba el Corriere della Sera-, y la quiebra del Banco Ambrosiano, fuertemente ligado al poder democristiano y a la Iglesia, cuyo presidente, Roberto Calvi fue encontrado colgado (¿vivo? ¿muerto?) del Blackfriars Bridge de Londres. En 1986 el banquero Michele Sindona (condenado a cadena perpetua por el asesinato del abogado Giorgio Ambrosoli, liquidador de uno de sus bancos) murió en la prisión donde permanecía bajo custodia. Estaba -se ha demostrado- muy cerca de la mafia y acababa de tomarse un café (precisamente como Gaspare Pisciotta, lugarteniente de Salvatore Giuliano, el «bandido» siciliano, cuarenta años atrás).

Además, la corrupción no afectaba sólo a las altas esferas. Podría decirse que se había extendido desde hacía tiempo a la conciencia de los ciudadanos, tranquilizados por el ejemplo de sus representantes -constantemente reelegidos de forma automática- y por la pérdida de confianza (y de miedo) en la ley, que se había convertido en algo vacío y puramente simbólico o instrumental; creada y suprimida por el poder para conseguir fines contingentes, para legitimar las injusticias, a veces incluso el crimen ${ }^{1}$. Y entonces, ¿por qué no explotar las oportunidades del sistema?, ¿por qué no construir nuestras casas sin licencia si podremos pagar en el momento oportuno para evitar su demolición?, ¿por qué no pedir a un tribunal una pensión de invalidez, si habrá un experto dispuesto a certificar una enfermedad que no existe y un juez dispuesto a no dudar del informe pericial?, ¿por qué renunciar a dar la cátedra a un discípulo aunque su nivel científico no sea suficiente,

${ }^{1}$ El recurso instrumental al Derecho penal, acompañado por la oportunidad de negociar amnistías substanciales y remisiones de penas, ha sido muy bien presentado por un penalista de la Universidad de Bolonia: F. Sgubbi, Il reato come rischio sociale. Ricerche sulle scelte di allocazione dell'illegalità penale, Il Mulino, Bologna, 1989. 
cuando sabemos que nuestro colega, «en nuestras mismas circunstancias», no dudaría en sacar adelante a su protegido, olvidando toda cuestión de valía?, ¿por qué no emplear a un trabajador sin inscribirlo en la Delegación de Trabajo, si esto le privará de sus derechos sindicales y por lo tanto debilitará su poder contra la empresa, y además nos permitirá ahorramos los gastos de seguridad social?

¿Es posible que una población que de buena o de mala gana, ha explotado todas las vías ilegales durante años se haya convertido de repente a la moralidad pública? ¿Es posible que esta población que en 1987 dio una mayoría aplastante a los partidarios del principio de la responsabilidad civil de los jueces, siguiendo los slogans de políticos que estaban desde hacía mucho tiempo bajo graves sospechas, haya comenzado de repente a buscar a sus héroes en los estrados de los tribunales?

\section{La crisis del Estado de bienestar y la crisis política}

No temeremos ser acusados de «sociologismo» (una etiqueta que ha sido sistemáticamente lanzada contra toda tentativa de explicación no irracional de los hechos sociales) diciendo que la crisis que ataca en Italia a la élite en el poder -hasta el punto de que ésta corre incluso el peligro de desaparecer- se ha desencadenado precisamente en el momento en el que nos hemos dado cuenta de que el Estado se estaba hundiendo bajo un déficit presupuestario espantoso (case el equivalente al PNB) y en consecuencia al encontrarse en un dilema: o imponer sacrificios a la mayoría de los ciudadanos, incluyendo una numerosa clientela política que constituye un grupo social en sí mismo; o agravar una imposición fiscal ya extremadamente fuerte no sólo por la presión de los impuestos directos, sino sobre todo por el alto nivel de los impuestos indirectos y de las contribuciones más o menos excepcionales que se cruzaban y multiplicaban sin cesar y sin respetar la equidad ni la racionalidad.

Por supuesto, esta crisis ya era vieja. Sobre ella se habían elaborado teorías tanto en Economía como en Sociología desde hacía ya mucho tiempo. Fue en 1973, durante la crisis del petróleo, cuando James O'Connor publicó su The Fiscal Crisis of the State; y, casi al final de los años 70, cuando Ralf Dahrendorf hablaba de la crisis del «consenso social-demócrata». Incluso en Italia, el debate se había mantenido vivo entre los partidarios de un análisis marxista, a la vez tradicional y renovado siguiendo la línea de Habermas, los neoliberales que iban al descubrimiento de la teoría de la elección pública, los seguidores de Niklas Luhmann, y los católicos a la búsqueda de un «tercer sector», el del solidarismo entre «Estado y Mercado». La literatura era ya muy abundante. 
Pero hubo algo que marcó la diferencia. En primer lugar, la crisis había tocado fondo, hasta el punto de que toda decisión (o falta de decisión) del poder no podía ser disfrazada, pues tenía efectos concretos e inmediatos sobre los ingresos de los ciudadanos. En segundo lugar, los compromisos asumidos a nivel europeo, en particular el Tratado de Maastricht, obligaban al Gobierno a denunciar públicamente la quiebra. Por una lado, no podíamos entrar en el SME a causa de la deuda pública; por otro lado, la red de relaciones comunitarias (otro de los problemas evidentes de control social) impedían tomar en consideración estrategias alternativas, por ejemplo una fuerte y oficial devaluación de la lira (se elegió la vía de una devaluación gradual y espontánea, saliendo del SME) que habría reducido drásticamente el déficit presupuestario de un golpe, en detrimento de las economías privadas.

En esta situación, la cuestión de la corrupción pública no podía dejar de explotar, aunque fuera simplemente por razones económicas y financieras. El sistema había sido denunciado ya varias veces e incluso estudiado con detalle ${ }^{2}$. Pero fue durante el año 1992 cuando se reveló en su estructura, simple y compleja al mismo tiempo, y en sus gigantescas proporciones. Todo gasto público hacia las empresas privadas, en el nivel del Estado o de la Administración local, estaba sometido a una deducción proporcional -entre un $10 \%$ y un $20 \%$, a veces más- en favor de los partidos políticos que tuvieran voz en la decisión: es la denominada tangente. Esto hubiera parecido incluso «normal» pese a estar previsto y penado en el Código penal. Pero el hecho es que en su gran mayoría -a partir de lo que se dice en los procesos judiciales- los gastos para las obras públicas aumentaron formidablemente, con la ventaja recíproca para los partidos, que ingresaban la tangente, y para las empresas, que ingresaban de 5 a 10 veces más del precio de mercado. Lo que sorprende, en este punto, es la dimensión del mecanismo que se presenta como general y sin excepciones, aunque gestionado en la cúspide por un privilegiado equilibrio entre empresarios y políticos de alto rango. Se emprenden cálculos y se comprueba que se trataba de varios billones de liras. En pocas palabras: el sistema podía incluso dar una explicación imprevista del déficit. El hecho de que las empresas pudieran utilizar

${ }^{2}$ Cfr. por ejemplo, F. Cazzola, Della corruzione. Fisiologia e patologia di un sistema politico, Il Mulino, Bolonia 1988, que ofrece un panorama general e histórico del proceso de corrupción; Id., L'Italia del pizzo. Fenomenologia della tangente quotidiana, Einaudi, Turín 1992, que describe los detalles del mecanismo de la corrupción en los diferentes sectores de la vida social; V. M. Caferra, Il sistema della corruzione. Le ragioni i soggetti, i luoghi, Laterza, Roma-Bari, 1992, que expone las condiciones jurídicas y políticas fundamentalmente de la debilidad de las estructuras estatales, que favorecen la prosperidad del sistema corrupto. 
el dinero suplementario para cubrir sus gastos e incluso conservar el nivel de empleo habría podido parecer una aplicación (aunque paradójica) de la lógica del Estado de bienestar³; este hecho fue señalado por algunos, pero al principio no impresionó demasiado. Algo que resultó más chocante fue la constatación de que la cantidad de las tangenti que terminó por estar en los bolsillos de los políticos de todos los niveles equivalía a cifras de nueve o diez ceros. Esto fue la catástrofe. Es el momento en el que se comprueba que «el rey está desnudo», en el que la prensa se lanza sobre los intocables de antaño sin ser ella misma tocada, en el que los jueces parecen poder trabajar sin ser amenazados, es el momento de la pérdida repentina de legitimación de la élite política de cara a la opinión pública, y en el que ésta presenta su cuaderno de quejas fiscales, bien fundadas, aunque es cierto que frecuentemente son los defraudadores los que se encuentran a la cabeza de la protesta: algo que, por otra parte, resulta normal en las explosiones de poujadismo.

¿Es necesario referirse explícitamente a los ejemplos históricos? ¿Es necesario acordarse de las razones expuestas para convencer a Luis XVI de que convocara los Estados Generales?

La similitud es evidente desde distintos puntos de vista. Ante todo, por la reacción del poder. Como en la Francia de 1789, en la Italia de 1992-1993 las élites que habían dominado la escena política durante cuarenta y cinco años parecían no comprender o no creer. Habían descuidado los signos premonitorios -las acusaciones catastróficas de Cossiga, el referéndum de 1991 (que había cambiado las reglas del juego para la elección de la cámara de diputados, reduciendo las posibilidades de alianzas oscuras entre candidatos)- y se lanzaban a las elecciones generales de 18 de abril de 1992; la ofensiva judicial ya había comenzado, precisamente como si nada hubiera sucedido, como si los problemas sólo existieran tras los muros del Palacio de Justicia. El impacto va a ser terrible; la mayoría histórica que había gestionado el país desde el fin de la guerra sólo tiene en el Parlamento unos cuantos escaños; esto es lo que provoca una revuelta de los opositores ocultos en los grupos parlamentarios, así como la caída inmediata de todos los líderes: Craxi, Forlani, Andreotti caen uno sobre otro -como los bolos- con motivo de la elección del presidente de la República y de las negociaciones para formar el nuevo gobierno. Pero incluso esta experiencia no sirve a la élite para modificar su estrategia. En la fase de confusión total que se abre entre 1992 y 1993, en plena avalancha judicial, asistimos a un final

${ }^{3}$ El fenómeno podría inscribirse en la práctica y en la teoría del intercambio político, como suele llamársele. En la literatura italiana, ver G. E. Rusconi, Scambio, minaccia, decisione. Elementi di sociologia politica, Il Mulino, Bolonia, 1984. 
paradójico. En lo referente a la ley electoral, los partidos de la coalición van pacíficamente al referéndum de junio de 1993, que dará una mayoría aplastante al sistema mayoritario con el apoyo instrumental, pero aparentemente convencido, de aquéllos ${ }^{4}$. El sistema mayoritario ya había sido introducido para la elección de alcaldes y de administradores locales, y en la primera votación, inmediatamente después, fueron aplastados sin piedad en favor de nuevos movimientos (como la Lega Nord o La Rete) o también de viejos ${ }^{5}$. Es entonces cuando se produce la tentativa desesperada y grotesca de diluir unas elecciones generales que podían cambiar la escena parlamentaria en un $80 \%$. La palabra «grotesca» se justifica si consideramos que la tercera parte de los parlamentarios elegidos en 1992 se encuentran ya acusados ante los tribunales o ante un juez penal y, aunque el Parlamento hubiera aprobado muy recientemente la abolición de la inmunidad parlamentaria, sigue haciendo falta el voto de la Cámara o del Senado para autorizar el arresto preventivo de alguno de sus miembros. Sólo el retraso de las elecciones legislativas puede salvar, entonces, a un tercio de los representantes populares del riesgo de la detención a la espera del proceso. Salvo, claro está, la alternativa que se propone en los pasillos: una solución «política» a los centenares de procesos por corrupción; es decir, una especie de amnistía general, más o menos disfrazada y negociada con la magistratura. La cuestión, por supuesto, está que arde y la guerrilla, que está en marcha, es precisamente uno de los factores que hacen correr el riesgo de que nadie se salve, ni siquiera el Estado en su estructura tradicional.

\section{La guerra de las instituciones}

Para una explicación de lo sucedido, también pueden extraerse algunos elementos útiles a partir de la historia reciente de los conflictos institucionales que han tenido lugar en el país, sobre todo los que han comprometido, por un lado, al poder político y, por otro, al

${ }^{4}$ Paradoja entre las paradojas: el sistema mayoritario ha sido sostenido no sólo por los grandes partidos, que serían los teóricamente favorecidos por éste, sino también, y sobre todo, por los que corrieron peligro de muerte política en el momento de su aplicación. Marco Pannella, el líder radical elegido para el Parlamento en 1992 por una minoría de menos del 2\% ha sido el paladín más resuelto de tal sistema, que él deseaba introducir «a la inglesa» (first past the post) y no en la forma atenuada elegida posteriormente por los legisladores (según la cual el $25 \%$ de los escaños es atribuido proporcionalmente).

${ }^{5}$ En las elecciones locales parciales de junio de 1993, que vieron a la Lega instalarse en casi todos los ayuntamientos del Norte, los neofascistas del Movimento Sociale Italiano consiguieron el doble de ayuntamientos que la Democrazia Cristiana. 
poder judicial, con la intervención ocasional de otros interlocutores sociales que actúan en el campo jurídico.

Es la historia de una alianza que sufre gradualmente una serie de dificultades, hasta el punto de transformarse en un conflicto abierto y total, en el clima de crisis general de la legalidad y del Estado de Derecho que acabamos de recordar.

La alianza surge y se desarrolla de una forma espontánea tras la Segunda Guerra Mundial entre una élite democrática, que fue inmediatamente poderosa, y una magistratura tradicional, débil en el plano político y económico, aunque distinguida como clase social. Es una magistratura con un débil poder discrecional y una débil responsabilidad, un grupo educado en el culto a la aplicación formal de la ley, aunque con cierta elasticidad llegado el caso; por otra parte, los mismos códigos permitían tal elasticidad cuando conviniera. Son los jueces formados en el ambiente del Estado fascista, donde la cultura jurídica formalista se encontraba contrabalanceada por el principio jerárquico y el metus reverentialis, hacia quienes estaban en la cumbre de la pirámide social.

La primera dificultad se produce cuando, en los años sesenta y comienzos de los setenta, una nueva generación de jueces aparece en escena y obtiene del poder político -gracias a una acción bien organizada y disfrazada bajo las formas adecuadas de derechos adquiridos según la ley existente- un reconocimiento en términos de rol, de status económico, de ascenso automático en la carrera y, sobre todo, de participación sustancial en la creación del Derecho. La «izquierda» judicial rechazó la aplicación «fría» de las leyes, fundamentalmente de las emanadas del régimen fascista, y reclamó la libertad de interpretar según el espíritu del momento, que unas veces se relacionaba con la Constitución democrática de 1948, y otras con las filosofías liberacionistas que dominaban el panorama cultural. Esto costó una escisión en la Associazione Nazionale Magistrati; los jueces más viejos y de más alto rango se negaron a seguir la nueva moda y reclamaron el principio de Montesquieu de «la bouche de la loi». Pero la escisión no impedirá a la Magistratura disfrutar de un gran poder discrecional y de una débil reponsabilidad. Lo que prevalece es la imagen del juez como «intérprete del conflicto social», más que de la ley; según la famosa definición de un sociólogo del Derecho,

${ }^{6}$ Una brillante reconstrucción de las reivindicaciones de los jueces de este periodo y de sus consecuencias en la política general fue hecha por E. Moriondo, L'ideologia della magistratura italiana, Laterza, Bari 1967, en el contexto de la investigación sobre «La administración de justicia y la sociedad italiana en transformación», organizada por el Centro Nazionale di Prevenzione e Difesa Sociale y dirigida por Renato Treves (ver su informe final, Giustizia e giudici nella società italiana, Laterza, Bari, 1972). 
Vincenzo Tomeo ${ }^{7}$ : el juez como representante de nuestra tendencia psicológica profunda en favor de la idea de Derecho natural.

Es fundamental subrayar que la élite política, aunque amenazada por el nacimiento de un verdadero poder alternativo que opera como «órgano de control social difuso» ${ }^{8}$, no se opone sustancialmente al proceder de los magistrados. Por supuesto existen algunas diferencias entre los partidos en lo referente al papel que debe desempeñar el juez. Pero la mayoría de centro-izquierda que gobernaba el país, por un lado, era «filosóficamente» favorable a un clima antiformalista y, por otro lado, suponía que podría sacar buen partido de la situación: descargar sobre los jueces los problemas más candentes que no podían encontrar solución política seria en el nivel legislativo. Se puede comprobar en la práctica que es en este periodo cuando la producción legislativa es más rica y, al mismo tiempo, vacía y simbólica. Las leyes son creadas sin orden alguno y a veces incluso sin contenido en vistas a su «libre» interpretación por el juez. Es el momento del protagonismo judicial, los jueces desempeñan el papel de «sustitutos» de los legisladores". Puede observarse que la alianza entre los dos grupos sociales oculta ya un conflicto latente.

Y el conflicto se manifiesta de golpe al final de los años setenta cuando, en pleno clima de batalla política, los jueces «que sustituyen» se convierten en el blanco de las reacciones sociales tanto de la derecha como de la izquierda. Un blanco trágico: los extremistas veían en los jueces obstáculos a derribar y los atentados fueron numerosos. Atentados instrumentales en el caso de la extrema derecha, que ataca a los jueces encargados de investigaciones específicas; más bien estratégicos y «simbólicos» en el caso de la extrema izquierda, que ataca a aquellos jueces que habían mostrado una apertura social, pues son ellos, «con su disfraz, los verdaderos enemigos del pueblo». Los círculos reformadores creados por los jueces «progresistas» son físicamente amenazados y atacados ${ }^{10}$.

La reacción de la magistratura no se hará esperar. A comienzos de los ochenta asistiremos a un giro total de la política de los magistrados, que habían conseguido de nuevo la unidad organizativa.

1972.

${ }^{7}$ V. Tomeo, Il giudice sullo schermo. Magistratura e politica nel cinema italiano, Laterza, Bari,

${ }^{8}$ M. R. Ferrarese, L'istituzione difficile. La Magistratura tra professione e sistema politico, Edizioni Scientifiche Italiane, Nápoles 1984, pág. 22. pássim.

${ }^{9}$ Ver, entre otros, M. Cappelletti, Giudici legislatori?, Giuffrè, Milán 1984; M. R. Ferrarese, op. cit.,

${ }^{10}$ Ver el testimonio de A. Beria di Argentine, un magistrado que ha ocupado puestos de responsabilidad tanto a nivel institucional, como en la Asociación de magistrados (Giustizia anni difficili, Rusconi, Milano, 1985). 
Todos reclaman la vuelta a la responsabilidad de la élite política: ahora es la izquierda judicial, Magistratura democratica, la que aboga por la fórmula de Montesquieu. La derecha, por su parte, quiere poderes excepcionales. Los obtendrá bajo la forma de leyes que darán lugar al fenómeno de los «arrepentidos». Leyes que -conviene subrayar- estaban formalmente limitadas a los grupos terroristas políticos, pero que produjeron una cultura, la cultura del pentitismo, más allá de los límites legislativos y absolutamente generalizada.

Pentitismo significa, en principio, colaboración del acusado con el Tribunal. Pero no consiste en el plea bargaining, el sistema americano que permite al acusado negociar las acusaciones y reducir la pena si admite la culpabilidad. En la extraordinaria situación italiana, pentitismo significa, en primer lugar, colaboración del acusado con la justicia y actitud de revelar los nombres y actos de sus camaradas. En segundo lugar -y aquí las reglas de juego del Estado de Derecho son cuestionadas- significa «derecho» efectivo, aunque no declarado, del arrepentido a ser creído en principio y, por tanto, a ser utilizado como prueba contra sus camaradas; y, correlativamente, «derecho» a obtener una recompensa inmediata, bajo la forma de libertad provisional e incluso a veces -podrían darse ejemplos dramáticos- de reducción de las acusaciones: algo que parece bastante contradictorio en un sistema basado oficialmente en la certeza del Derecho penal y, a diferencia del sistema americano, en el carácter obligatorio de la actuación penal por parte del Ministerio público ${ }^{11}$.

Conviene partir de aquí para comprender cómo el conflicto entre políticos y jueces se convirtió en un conflicto abierto y áspero cuando las medidas judiciales excepcionales comenzaron a ser utilizadas en investigaciones que implicaban a los políticos o a las bases menos limpias de sus poderes locales: esto es, los procesos contra las asociaciones con fines delictivos, sobre todo por los casos de corrupción administrativa organizada, en los que los «arrepentidos» son utilizados, sin cesar y sin límites, para obtener informaciones y multiplicar así las investigaciones y los arrestos. Informaciones veraces e informaciones falsas, claro está. La magistratura está tan involucrada en la aventura del pentitismo que se expone a terribles derrotas, derrotas que el sistema de partidos explota inmediatamente. El proceso en el que el showman Enzo Tortora fue condenado, probablemente a partir de un caso de homonimia posteriormente «enriquecido» por calumnias deliberadas (los «arrepentidos» dicen normalmente

${ }^{11}$ Ferrajoli ha formulado una severa y minuciosa crítica a la «ineficacia de las garantías en el Derecho penal italiano», en el contexto de una teorización general de gran nivel (Diritto e ragione. Teoria del garantismo penale, Prefacio de N. Bobbio, Laterza, Roma-Bari, 1989). 
lo que el investigador «desea» que ellos digan, aunque sea necesario inventar) ${ }^{12}$, se convierte en símbolo y bandera de una batalla anti-jurídica que reagrupa fuerzas bien distintas y que durará hasta el fin de la década. Junto a los defensores del garantismo están los que aspiran principalmente a evitar lo peor. Junto a los paladines del pobre Tortora (felizmente elegido al Parlamento europeo como símbolo de la batalla por la «justicia justa» y posteriormente absuelto por la Corte de Apelación) están los que se reunieron en Savona en junio de 1983, una semana después del arresto de Alberto Teardo (presidente del Gobierno regional) y de sus compañeros, todos ellos bajo acusación de corrupción y concusión sistemáticas (agravadas por el recurso a amenazas violentas), para decir públicamente que se trataba de «prisioneros políticos» ${ }^{13}$, como en el caso de Ferruccio Parri y de Carlo Rossell y acusados, medio siglo antes en la misma ciudad, por el régimen fascista de haber favorecido la expatriación clandestina de Filippo Turati.

La batalla que se desencadena entre los dos poderes a partir de 1983 tendrá su colofón en 1987 con la consulta, vía referéndum, sobre la cuestión de la responsabilidad civil de los jueces. En relación con ésta los proponentes del referéndum denunciaban los límites previstos por el Código de enjuiciamiento civil. Es una cuestión de técnica jurídica y carente de relevancia práctica que se presenta en términos retóricos y dramáticos, como si de ello dependiera la solución a todos los problema de la justicia. A parte de los defensores directos -entre ellos el Partido Radical, que inauguró la batalla sobre el asunto Tortora, y el Partido Socialista, que lo asumió a su cargo con un índice de entusiasmo al que el asunto Teardo no es completamente ajeno-, los otros partidos políticos, salvo pequeñas excepciones, se encuentran muy molestos, pero fundamentalmente tienen miedo a que el referéndum

${ }^{12}$ Puede recordarse el caso simbólico de un inculpado «arrepentido» que «conduce» a la policía a la casa de otro inculpado para mostrar de visu el lugar donde, según su declaración, había visto a éste último cargar un cadáver, jamás encontrado. El testimonio del arrepentido fue considerado como una prueba decisiva y dio lugar a un año de aislamiento suplementario para el acusado. Este era periódicamente invitado a suministrar datos y nombres, hasta el momento en el que, en la víspera del proceso, se le reveló cuál era exactamente la casa de la que se hablaba, lo que le permitió alegar que él la había abandonado un año antes del hecho denunciado, por haber sido desahuciado, a causa de su deuda con el propietario. El proceso mostró que ambos jamás se habían conocido antes de la investigación judicial y terminó con la condena del «arrepentido» por calumnia.

${ }^{13} \mathrm{La}$ importancia «histórica» de este asunto y del proceso que lo resolvió es notoria para los observadores de la política italiana de los años ochenta y ha sido recientemente subrayada, por ejemplo, en el excelente estudio de D. della Porta, que le ha dedicado un análisis detallado (Lo scambio oeculto. Casi di corruzione politica in Italia, prefacio de A. Pizzorno, Il Mulino, Bolonia, 1992). 
se apruebe y a encontrarse en el 
bando de los perdedores. Esto llevará a una amplia mayoría a votar y, concretamente, a favor del «sí» a la abolición de los artículos de que se trataba; aunque la minoría de opositores obtendrá, con aproximadamente el $20 \%$, bastante más que el porcentaje teórico de los partidos que habían pedido el «no»» ${ }^{14}$.

Es el momento de mayor debilidad de la Magistratura italiana, que vive el referéndum como un insulto, mucho más allá de los efectos concretos del resultado. Y es el momento en el que, bajo la dirección socialista del Ministerio de Justicia, la élite en el poder lanza la ofensiva que habría de ser decisiva. Por un lado, el Código de enjuiciamiento criminal, el primer código de la Italia postfascista, inspirado en el principio acusatorio, fue finalmente introducido en un clima de sospecha y a veces de sabotaje -veremos que injustificado- por parte de los jueces. Por otro lado, se proyecta una reforma con el propósito de reconducir las funciones del Ministerio Público bajo el control político centralizado del Ministerio de Justicia, como antes de la guerra. Fundamentalmente se atacan los privilegios de los magistrados, sus asociaciones, su influencia política, su organización institucional. El combate es especialmente fuerte entre el Presidente de la República, que preside el Consiglio Superiore della Magistratura, y los miembros del Consejo elegidos por los jueces.

La clase política permanece inmóvil en su poder, fortificada por una sólida mayoría parlamentaria, que no llega a impedir las conspiraciones de palacio, pero que sostiene un Gobierno de coalición sin alternativas y que disfruta de un poder inmenso. La legislatura comenzada en 1987 será la primera, desde 1968, que consiga agotar su término natural de cinco años. Pero entre los bastidores de la Corte política no se percibe el precio que el país está pagando bajo la forma de ilegalidad miserable, de déficit presupuestario fuera de control, de especulaciones y de desorientación social. Como le sucedía a Luis XVI, apenas se ve lo que sucede más allá de las murallas, en la sociedad.

Es en este momento, tras la «sorpresa» electoral de 1992, de la que ya hemos hablado, cuando se presenta la crisis final de las relaciones entre el poder judicial y el poder político, lo que se acaba de definir como la avalancha judicial.

Los instrumentos estaban preparados. El Código de enjuiciamiento criminal hecho por los juristas progresistas y demócratas, a

${ }^{14}$ La batalla por el «no», perdida desde el principio, fue combatida por el Partito Repubblicano Italiano (de orientación liberal tecnocrática) y, por Democrazia Proletaria (de orientación comunista libertaria, cuyo manifiesto fue inspirado por el filósofo del derecho Luigi Ferrajoli) y por intelectuales aislados, como Norberto Bobbio, a los que también se unió el autor de este artículo. 
los que la Magistratura temía, se revela (gracias también a «pequeños» cambios) bastante más manejable de lo que se había pensado. La informatización de los despachos es casi completa y permite el acceso rápido a las informaciones. El antagonista parecía distraído por su misma fuerza. Lo que faltaba era la ocasión, que se presentará -aunque había sido buscada insistentemente- cuando un administrador local socialista, presidente de un organismo de asistencia, es cogido in fragranti por la policía en el momento en que se embolsaba una tangente de unos cuantos millones de liras. Arrestado, será tratado como «ratero» (mariuolo) por el líder de su partido, algo que provocará su resentimiento. Y, por otro lado, su esposa separada hablará de las maniobras que realizaba su marido para ocultarle las riquezas que tenía en Suiza: se trataba -según se dice- de riquezas extraordinarias, si se considera el modesto nivel político del personaje. El hombre hablará, describirá a los investigadores que le interrogan los detalles del sistema, se convertirá en su «maestro», como manifestará agradecido un fiscal de la República. Será el extremo de un hilo del que bastará estirar para deshacer el traje entero. Es así como comienza una serie de arrestos, según la técnica muy practicada del pentitismo. Con una diferencia ahora: que las confesiones de los acusados, aunque motivadas por el deseo de abandonar la prisión, son generalmente ciertas. Y la magistratura ascenderá rápidamente desde la base hasta lo más alto de la pirámide política e industrial. Las investigaciones se multiplican, invaden el Parlamento, le obligan a decidir sobre uno u otro miembro, a dar autorización para someterlo a un proceso. Se pone en marcha un mecanismo casi automático. Unos y otros -políticos y empresarios- lo admiten. Unos dicen que es normal, que la única ley que ha sido violada es aquélla, obsoleta, que regula la financiación pública de los partidos políticos. Los otros se presentan como víctimas: sin pagar no se podía trabajar. Es la única manera que tienen de escapar a la acusación de corrupción: lanzar sobre los políticos la acusación de concusión. La magistratura tira del hilo sin parar, un acusado tras otro. Por supuesto las reacciones no faltan, pero muestran fundamentalmente arrogancia, presunción, o pura y simple torpeza.

\section{La sombra de Hobbes: i»bellum omnium contra omnes»?}

Si el sistema de gestión política está generalizado, se entiende bien que el hilo del que se estira sea infinito. En el vacio político que se produce entre 1992 y 1993, las iniciativas se extienden desde Milán, donde habían surgido, a toda Italia. Los tribunales que tenían miedo, o que parecían ellos mismos ligados -ideológica, 
instrumentalmente- al sistema, se lanzan a una ofensiva por todo el territorio de la península, en un clima de emulación creciente, favorecido por la notoriedad aduladora ofertada por los medios. Se atreven a enfocar hacia las altas esferas. Desentierran los dossiers de entre el polvo de los cajones y a veces de los archivos. Reconstruyen los hechos y las circunstancias. Ahondan en los misterios oficiales del país, esos de los que se conoce casi todo, pero sólo por murmullos. Intentan buscar también la explicacion de algunos misterios reales. Aparecen o reaparecen sombras en escena, todas juntas. Aldo Moro y las Brigate Rosse, las negociaciones secretas sobre su vida; los contactos más o menos estructurados entre mafia, camorra y Estado; el fantasma de Roberto Calvi y de sus dossiers desaparecidos y vendidos; el comercio internacional de armas y sus especuladores; los atentados y las masacres de inocentes; los pagos prohibidos hechos por los servicios secretos para liberar a los rehenes de las manos de la $n^{\prime}$ drangheta calabresa o de los bandidos sardos; el dinero negro de los servicios secretos y su explotación por los ministros; hasta los proyectos y tentativas de golpe de Estado (los últimos, que implicaban a militares de alto rango, fueron revelados con el perfil de una astracanada).

Todos acusan a todos. Se denuncia el hecho de que dos antiguos ministros de interior tenían estrechas relaciones con la camorra; que un antiguo presidente del consejo fue miembro de la mafia; que las masacres habían sido organizadas por los servicios secretos; que la corrupción contaminaba a la magistratura; que las catástrofes financieras habían sido instrumentalmente provocadas; que las especulaciones habían afectado a la salud de los ciudadanos, por la utilización de plasma sanguineo infectado, precisamente igual que en Francia; que todas las medicinas eran aceptadas por el ministerio competente a cambio de los correspondientes pagos de tangenti dignas de un Gran Faraón. Los sectores católicos anuncian que todo depende de las logias masónicas; los sectores laicos les devuelven la pelota y subrayan el papel de la Iglesia en los asuntos financieros más oscuros. Los arrestos se suceden uno tras otro de forma acelerada, haciendo los periódicos y las televisiones un espectacular seguimiento diario. Finalmente, en el desorden de los últimos días de otoño de 1993, las sospechas golpearán al primer ministro y al Presidente de la República.

Se denuncia, se sospecha, se condena en el nivel de los medios de comunicación de masas, sin que se haya celebrado ningún proceso, sin que se haya dictado ninguna condena en forma definitiva; muchos acusados son detenidos hasta que se deciden a «colaborar». Pero recordar la presunción constitucional de inocencia, condenar el recurso instrumental a la detención para obtener confesiones, 
pocas palabras, recordar a Cesare Beccaria en una atmósfera de riesgo como ésta, desgraciadamente hace sonreir o provoca las invectivas habituales contra la «justificación de las garantías», normalmente acompañadas por los elzevirios de algunos periodistas disfrazados de historiadores, que atribuyen la responsabilidad de todo lo que pasa a sociólogos o viejos estudiantes de 1968.

En un clima de confusión total, que se traduce en especulaciones diarias con la lira y que agrava la crisis económica y el desempleo -las grandes empresas declaran estar en crisis total por la paralización de las obras públicas-, ni siquiera la oposición sabe qué hacer. Los que más atacan al Presidente de la República temen que éste dimita, pues esto retrasaría las elecciones generales. Los que lo habían elegido desean con agrado que dimita, para prolongar su mandato por algunos meses. Y las elecciones legislativas futuras aparecen como un acontecimiento catártico más allá del cual nadie osa pensar.

¿Habrá un federalismo oficialmente proclamado por la Lega Nord, o lisa y llanamente la secesión del Norte, como sueña su ideólogo oficial Gianfranco Miglio? ¿O bien todo esto terminará con una tormenta de verano, barriendo de un solo golpe la enfermedad, como en Los novios de Manzoni? Y finalmente ¿qué enfermedad va a desaparecer bajo la lluvia? ¿La corrupción o el moralismo que aspira a sanarla?

Aunque el porvenir inmediato no pueda preverse, hay una hipótesis, sugerida por la Historia de la sociedad humana, que parece razonable. La corrupción, un término que designa fundamentalmente la actitud generalizada de practicar una doble moral es más endémica que el moralismo. Además, su correlación con la riqueza del Estado moderno es evidente; esto explica por qué preocupa e indigna sobre todo en los períodos de crisis, durante los cuales hay un temor difuso a perder las ventajas habituales ${ }^{15}$. Y, por tanto, sus posibilidades de éxito en el futuro son mayores que las del moralismo, aunque sólo sea porque los vencedores del conflicto político no tendrán ningún interés en las campañas de moralización, una vez que hayan aprovechado las ventajas, o que se hayan salvado. Y entonces puede suponerse que, con cualquier gobierno, los italianos volverán de nuevo a las viejas costumbres -quizá un poco inmorales, pero tan tranquilizadoras...-. En el momento e $\mathrm{n} \quad \mathrm{q}$ u e 1 a $\quad \mathrm{c}$ r i s i s e c o n ó $\mathrm{m} \mathrm{i} \mathrm{c} \mathrm{a}$

${ }^{15}$ La relación entre la riqueza del Estado moderno y el aumento de los índices de corrupción pública ha sido constatada por los sociólogos del Derecho: ver al respecto las actas del seminario organizado por el Comité de Investigación de Sociologia del Derecho de la Asociación Internacional de Sociología en Caracas en 1989, publicados por R. Pérez Perdomo y R. Capriles (Corrupción y control. Una perspectiva comparada. Ediciones IESA, Caracas, 1991). 
haya alejado, un Principe, independientemente de que sea viejo o nuevo, será sentado sobre el trono y el viento de la indignación dejará de soplar. Esperemos que, y ésta es la variable inquietante, no se dejen arrastrar en los juegos de facciones, como los yugoslavos, y que se unan fuertemente a Europa a pesar de todas sus inmoralidades ${ }^{16}$.

\section{Apéndice de actualización (y de verificación)}

Todo lo anterior constituye un intento de comprensión de lo que ha acontecido en Italia en los últimos tiempos ${ }^{1}$. No es por tanto, simplemente una historia abreviada, ni tampoco una crónica. También se ha intentado trazar algunas hipótesis razonables sobre la futura evolución de un sistema de relaciones sociales, cosa que precisamente compete a un sociólogo del Derecho. Así, desde el otoño de 1993, cuando se escribió el artículo, el juicio del autor quedó en cierto modo suspendido, a la espera de ver si los acontecimientos posteriores confirmaban o no las previsiones.

Estos acontecimientos, que se han sucedido a gran velocidad entre 1993 y 1995 , son bien conocidos también internacionalmente y no es necesario describirlos. Bastará recordarlos en lo esencial, por cuanto hace a los fines de nuestra discusión. El invierno 1993-1994 transcurrió en una espera espasmódica de elecciones políticas a celebrarse según una ley electoral mayoritaria, cuyo mecanismo ha llevado al gobierno a una «pequeña mayoría» ${ }^{2}$ (en realidad una concentración

${ }^{16}$ Sobre las etapas y protagonistas de la crisis política en Italia, hay una literatura bastante abundante, sobre todo de estilo periodístico o directamente político: cfr. por ejemplo, G. Pansa, L’anno dei barbari, Sperling \& Kupfer, Milán, 1993; E. Biagi, La disfatta, Rizzoli, Milán, 1993; G. M. Bellu y C. Bonsanti, Il crollo, Laterza, Roma-Bari, 1993; N. dalla Chiesa, Milano-Palermo, la nuova resistenza, Baldini e Castoldi, Milán, 1993; U. Bossi y D. Vimercati, La Lega: storia e idee, Sperling \& Kupfer, Milán, 1993. A un nivel más politológico, cfr. por ejemplo, I. Diamanti, La Lega. Geografia, storia e sociologia di un nuovo soggetto politico, Donzelli, Roma 1993; S. Romano, L'ltalia scappata di mano, Longanesi, Milán, 1993.

${ }^{1}$ En la literatura más reciente sobre la crisis italiana, véase el reciente libro de P. Sylos Labini, titulado precisamente La crisi italiana, Laterza, Roma-Bari, 1995.

${ }^{2}$ La idea de que lo que tenemos sea «una buena, pequeña mayoría», expresión acuñada por Benjamin Disraeli, ha sido retomada recientemente por G. Rebuffa en su libro La costituzione impossibile, Il Mulino, Bologna, 1995, tendiendo a reivindicar una reforma constitucional basada en el modelo británico e inspirada en una idea lockeana de los derechos individuales (pero susceptible de proporcionar argumentos a quien propugna el derecho de las «pequeñas mayorías», o minorías disfrazadas de mayorías, de imponer su propia voluntad a toda una ciudadanía). 
de minorías) que ha intentado, como primer objetivo, precisamente paralizar por decreto-ley las investigaciones judiciales que amenazaban a sus propias cúpulas dirigentes. Naturalmente, la razón aducida ha sido una apelación al garantismo procesal, violado, según el gobierno, con el uso instrumental de la prisión preventiva. Pero las discriminaciones entre distintos tipos de delito, que confirmaban la estrategia ya experimentada de construcción de un doble sistema de justicia, han sido tan evidentes y descaradas que han provocado reacciones sociales imprevisibles y, como consecuencia, la crisis misma de la coalición, aireada day-today, durante cuatro meses, entre protestas, denuncias, rumores de golpes de estado inminentes, histerias... La «pequeña mayoría», sin darse cuenta de ser ya una minoría, ha insistido en la lucha llevando el enfrentamiento con la judicatura hasta el límite máximo de intensidad, cuando los inspectores ministeriales fueron enviados a investigar las actuaciones judiciales más incisivas. Después de aquello, como todos sabemos, hemos asistido a la caída del gobierno y a enfrentamientos políticos de inusitada vehemencia. El futuro, a pesar de algunos signos de arrepentimiento, sigue siendo incierto.

Se lucha furiosamente en términos de legitimación y deslegitimación. Pero ahora es sobre todo lucha de imagen, en la que este concepto se vuelve cada vez más efímero y caduco. Ya ni siquiera es la imagen lo que cuenta, sino su reflejo televisivo. Las figuras-símbolo se exaltan y se queman en una orgía mediática, en la suposición de que el público se quede impresionado.

Y aquí está, quizá, el error de fondo en el que la clase política aparece todavía prisionera. La gente podría volverse refractaria al bombardeo de símbolos, muchos de ellos artificiales, y reaccionar con un disenso ya no explícito, sino silencioso. Hace setenta años Piero Gobetti dijo de Mussolini que éste había interpretado «la vocación de los italianos en reposo», es decir, que había explotado su cansancio. Hoy, el cansancio de la gente podría volverse en contra de los manipuladores de la opinión pública e inducirla, ya no a delegar el poder, sino a gestionarlo directamente. Ello significa hacer del ejercicio del poder un deber -deber de arbitrar equitativamente entre intereses en conflicto- y ya no un privilegio. ¿Viviremos lo bastante para ver realizada esta utopía liberal?

(Trad. de Isabel Lifante Vidal y Victoria Roca Pérez) 